\title{
The influence of the COVID-19 epidemic on the gastrointestinal endoscopy practice in China: a national survey
}

\author{
Ningli Chai ${ }^{1} \cdot$ Xiaowei Tang $^{1}$ (1) Enqiang Linghu ${ }^{1}$. Jiancong Feng ${ }^{1} \cdot$ Lu Ye $^{1} \cdot$ Qingzhen Wu $^{1} \cdot$ Xin Zhao $^{1}$. \\ Runxiang $\mathrm{Du}^{1}$ · Longsong $\mathrm{Li}^{1}$. Wengang Zhang ${ }^{1}$. Jingyuan Xiang ${ }^{1}$. for the COVID19 Working Group of the Chinese \\ Society of Digestive Endoscopy
}

Received: 6 August 2020 / Accepted: 3 November 2020 / Published online: 11 November 2020

๑) Springer Science+Business Media, LLC, part of Springer Nature 2020

\begin{abstract}
Background and Aim With the worldwide spread of coronavirus disease 2019 (COVID-19), it has devastated the economy and taken a toll on people' life in every aspects. In this study, we aimed to evaluate the influence of the COVID-19 epidemic on the GI endoscopy practice in China.

Methods The nationwide survey conducted from 13 to 19 April, 2020. A predesigned standard structured questionnaire was sent to all members of the Chinese Society of Digestive Endoscopy (CSDE) in mainland China by email. Number of various GI endoscopic procedures and participants getting endoscopic training from January 1 to April 10, 2020 (the COVID-19 period) and the same period of 2019 were collected and analyzed.

Results A total of 468 hospitals responded to this survey, and most of them (85.4\%) were tertiary referral hospitals. The sum number of GI endoscopic procedures deceased significantly from 3,203,594 in 2019 to 1,512,619 in 2020, including $2,996,779$ to $1,401,665$ of diagnostic procedures and 206,815 to 110,954 of therapeutic procedures. More than half of centers (57.1\%) reduced about 1,000-5,000 endoscopic activities. Of 271 hospitals (57.9\%) providing endoscopic training, the total number of participants decreased from 2,977 in 2019 to 1,131 in 2020. Most of hospitals (93.8\%) adhered to the recommendation of endoscopy practice issued by CSDE during the outbreak of COVID-19, and there was no cases of infection in endoscopic departments of all surveyed hospitals.

Conclusion With the influence of the COVID-19 epidemic, there has been significant decease of GI endoscopy practice in mainland China.
\end{abstract}

Keywords COVID-19 · Gastrointestinal endoscopy · Influence · China

Since coronavirus disease 2019 (COVID-19) initially emerged in Wuhan, China in early December 2019 [1], it has become a global pandemic, and posed a severe threat to human health and lives. According to the World Health

Ningli Chai and Xiaowei Tang have contributed equally to this study.

Electronic Supplementary Material The online version of this article (https://doi.org/10.1007/s00464-020-08149-4) contains supplementary material, which is available to authorized users.

Enqiang Linghu

linghuenqiang@vip.sina.com

1 Department of Gastroenterology, The First Medical Center of Chinese PLA General Hospital, No. 28, Fuxing Road, Haidian District, Beijing 100853, China
Organization (WHO), COVID-19 is estimated to have resulted in 2,203,927 cases in 213 countries with 148,749 deaths as of April 19, 2020, among which highest confirmed cases were detected in United States [2].

Due to the risks of virus transmission by respiratory and oropharyngeal secretions and colonic contents, endoscopy is regarded as a risky procedure [3]. All major gastrointestinal (GI) or GI endoscopy societies have recommended non-urgent procedures should be rescheduled or canceled and emergent case need to be performed based on the clinical need [4-9]. In addition, unprecedented strict quarantine measures were implemented in China, and a large number of people were kept in isolation. That caused a series of medical examinations and activities to be canceled. Therefore, in this study, we aimed to evaluate the influence of the COVID-19 epidemic on the GI endoscopy practice in China 
for different aspects: (a) changes of various endoscopic procedure volume, (b) impact of COVID-19 on endoscopic training.

\section{Materials and Methods}

\section{Survey administration}

The nationwide survey was initiated and organized by the Chinese Society of Digestive Endoscopy (CSDE), and conducted from 13 to 19 April, 2020. A predesigned standard structured questionnaire was sent to all members of the society in mainland China by email. If the first request was not answered, further reminders by email, telephone calls and WeChat (a widely used social media in China) were initiated. After completed by the chief or senior physician of each endoscopic center, the questionnaires were returned to the CSDE headquarters in Beijing for analysis. No incentive was offered for participants in this survey. Our research did not require IRB approval and written consent.

\section{Questionnaire}

The questionnaire included 27 questions and the following five sections (Supplementary Table 1): (1) Baseline characteristic of hospital and endoscopy centers, including hospital grading and ownership, endoscopic room scale and others; (2) During the pandemic, whether performing GI endoscopic procedure in accordance with recommendations of CSDE? [10] (3) Number of diagnostic GI endoscopic procedures from January 1 to April 10, 2020 (the COVID-19 period) and the same period of 2019, respectively, including esophagogastroduodenoscopy (EGD), colonoscopy, enteroscopy, capsule endoscopy and others; (4) Number of therapeutic GI endoscopic procedures during the above two periods, including ERCP, interventional EUS and others. (5) Number of participants getting various endoscopic training during the above two periods, including training in endoscopic detection of early GI cancer, endoscopic resection, ERCP, EUS and other techniques.

\section{Data collection and synthesis}

Data from returned form was extracted and summarized in a database for further analysis. The total number of GI endoscopic practices in each provincial region was accumulated. To analyze the changes of overall GI endoscopy activities in various regions, the mainland China was divided into four parts: northeast, east, central, and western regions. The cumulative confirmed COVID-19 cases in different regions of China on April 10, 2020 was accessed at the official website of Chinese Centers for
Disease Control [11]. The average procedure volume per endoscopist at each province during the epidemic was calculated as the sum number of procedures divided by the total number of endoscopists.

\section{Statistical analysis}

Categorical data was presented as percentages. Pearson test was used to analyze the correlations between average procedure volume per endoscopist and cumulative confirmed COVID-19 cases up to April 10, 2020. The data were analyzed using SPSS ${ }^{\circledR}$ version 20.0 software (IBM, Armonk, New York, USA). A $p$ value $<0.05$ (two-sided) was regarded as statistically significant.

\section{Results}

Surveys were distributed to 589 hospitals, and a total of 488 forms were returned. After removing invalidation and duplicates, there were 468 (79.5\%) completed forms left.

\section{Baseline characteristics of GI endoscopy centers}

As shown in Table 1, of the 468 hospitals surveyed, most $(85.4 \%)$ were tertiary referral hospitals, and the majority (86.4\%) were college-affiliated hospitals. There were 54 hospitals (12.0\%) with endoscopic room scale $\geq 2000 \mathrm{~m}^{2}$, and more than half of hospitals (69.8\%) with endoscopic room scale less than $1000 \mathrm{~m}^{2}$. As for endoscopic unit personnel, the total number of endoscopists and nurses were 5044, 4,397, respectively.

Table 1 Baseline characteristic of surveyed hospitals

\begin{tabular}{lr}
\hline & $N(\%)$ \\
\hline Hospital grading & \\
$\quad$ Tertiary referral hospitals & $699(85.4)$ \\
$\quad$ Non-Tertiary referral hospitals & \\
Hospital ownership & $400(86.4)$ \\
$\quad$ College-affiliated hospitals & $63(13.6)$ \\
$\quad$ Non-college-affiliated hospitals & \\
Endoscopic unit scale & $54(12.0)$ \\
$\geq 2000 \mathrm{~m}^{2}$ & $82(18.2)$ \\
$2000-1000 \mathrm{~m}^{2}$ & $315(69.8)$ \\
$\quad<1000 \mathrm{~m}^{2}$ & \\
No. of endoscopic unit personnel & $5044(53.4)$ \\
Doctor & $4397(46.6)$ \\
$\quad$ Nurse &
\end{tabular}




\section{Changes of various $\mathrm{Gl}$ endoscopic procedure volume}

The changes of GI endoscopic volume in various regions between 2019 and 2020 was presented in Fig. 1 and Supplementary Table 2. From January 1 to April 10, 2019, the sum number of GI endoscopy was 3,203,594, including 2,996,779 diagnostic endoscopic procedures and 206,815 therapeutic procedures. During the same period of 2020, the total number decreased significantly, which was nearly half of that in 2019 ( $n=1,512,619,1,401,665$ diagnostic and 110,954 therapeutic procedures). Based on number of procedure reduction, $57.1 \%$ centers reduced about $1000-5000$ endoscopic activities, and 5.8\% centers reduced more than 10,000 endoscopic activities (Fig. 2).

The highest number of reduced procedures was in Beijing, reached up to 193,183 . As the top high-risk provincial

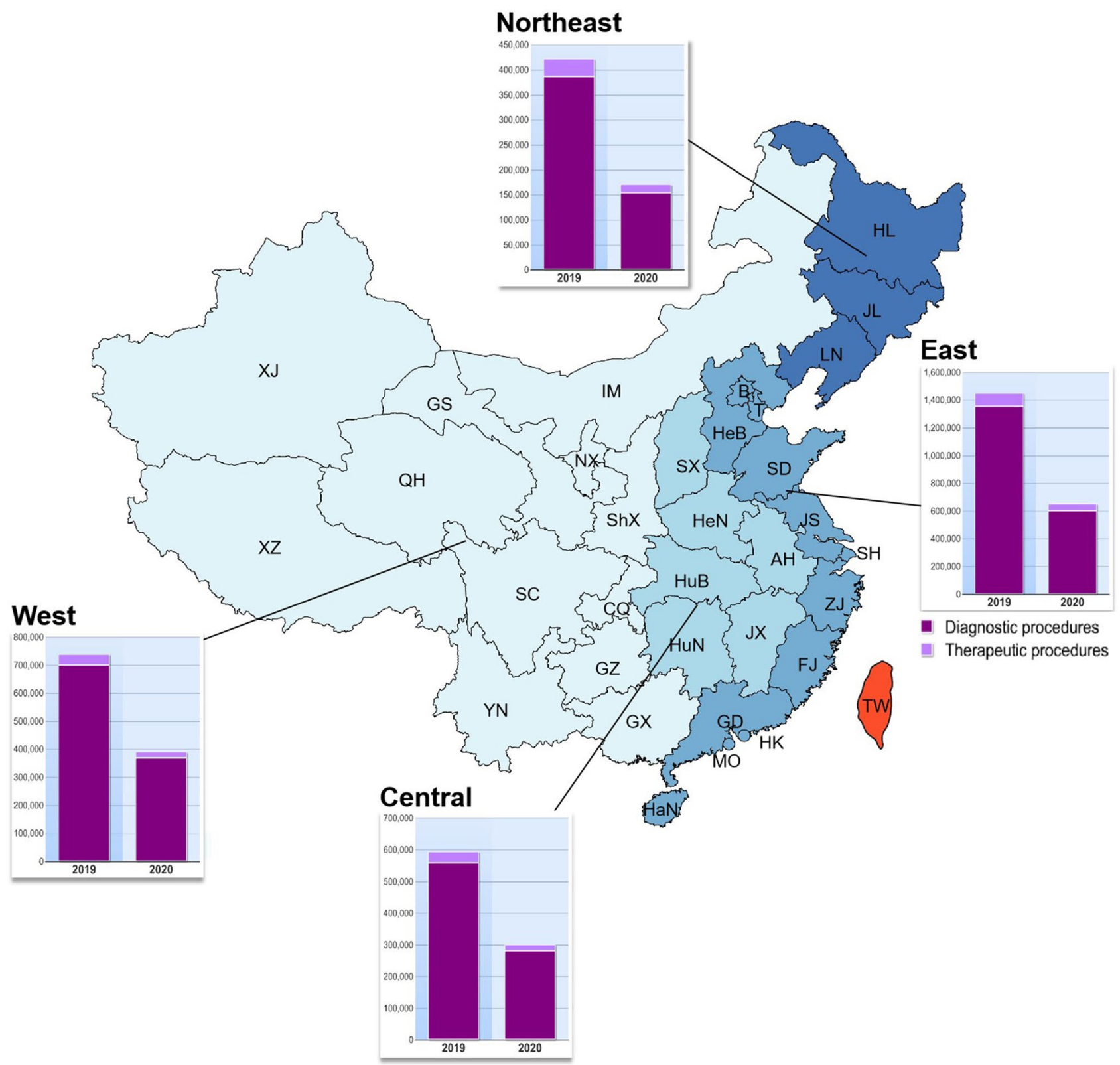

Fig. 1 Changes of overall GI endoscopy activities in the 31 provinces of mainland China between January 1 to April 10, 2019 and the same period of 2020. (Northeast region: HL, Heilongjiang; JL, Jilin; LN, Liaoning. East region: BJ, Beijing; FJ, Fujian; GD, Guangdong; HaN, Hainan; HeB, Hebei; JS, Jiangsu; SD, Shandong; SH, Shanghai; TJ, Tianjin; ZJ, Zhejiang. Central region: AH, Anhui; HeN, Henan;
HuB, Hubei; HuN, Hunan; JX, Jiangxi; SX, Shanxi. West region: GS, Gansu; GX, Guangxi; GZ, Guizhou; IM, Inner Mongolia; NX, Ningxia; QH, Qinghai; ShX, Shaanxi; SC, Sichuan; XZ, Tibet; XJ, Xinjiang; YN, Yunnan; CQ, Chongqing. HK, Hong Kong; MAC, Maocau; TW, Taiwan) 


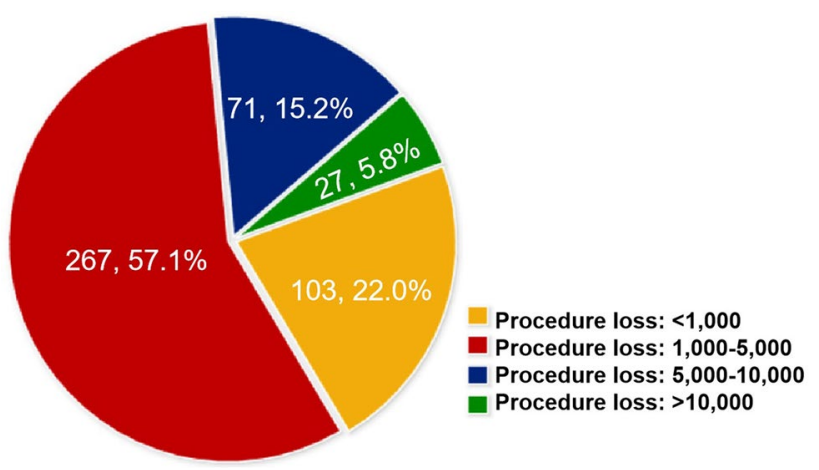

Fig. 2 Proportions of hospitals with different reduced number of GI endoscopic procedures

regions of mainland China, Hubei, the reduced number of endoscopic procedures was 53,984, but the losses ratio of procedures (the volume in 2020/the volume in 2019) was $20 \%$, ranked first among all regions (Supplementary Table 2). There was a significant correlation between average procedure volume per endoscopist and cumulative confirmed COVID-19 cases $(r=-0.372, p=0.04)$ during the epidemic. Changes of GI endoscopic procedures volume per months was shown in Fig. 3. During the outbreak period, the highest procedure reduction was on February. From February to March, 2020, the number of procedures began to increase, and get recovered as to that in 2019.

Regarding to diagnostic procedures, the most reduction number was in EGD $(n=1,039,714)$, followed by colonoscopy $(n=466,549)$ (Fig. 4). With respect to therapeutic procedures, the greatest reduction was in endoscopic resection of colorectal lesion $(n=47,249)$, followed by endoscopic resection of gastric lesion $(\underline{n}=20,375)$ (Fig. 5).

\section{Impact of COVID-19 on GI endoscopic training}

There are 271 hospitals (57.9\%) providing endoscopic training. Of those, the total number of endoscopists getting training decreased from 2977 in 2019 to 1131 in 2020 (Fig. 6). Based on training patterns, the number of participants deceased from 280 to 115 for ERCP, 344 to 126 for EUS, 486 to 167 for endoscopic resection technique, 795 to 315 for endoscopic detection of early GI cancer, and 1072 to 408 for EGD and colonoscopy, respectively.

\section{COVID-19 prevention and control measures}

Most of hospitals (93.8\%) adhered to the recommendation of endoscopy practice during pandemic issued by CSDE. There was no cases of infection in endoscopic departments of surveyed hospitals.

\section{Discussion}

In the past 4 months, a novel coronavirus (SARS-CoV-2), leading to COVID-19, has rapidly spread throughout the world. Due to its high infectivity and morbidity, WHO has declared COVID-19 as a global pandemic on March 11,2020 . The sheer scale and severity of this pandemic is unprecedented in the modern era. At present, COVID-19 has affected more than 200 countries, and the newly confirmed case is increasing everyday [2]. This disease has devastated the economy, presents a significant challenge to the healthcare system worldwide. According to the literature, the impact of COVID-19 in some medical specialities are also very evident. Lisi and his coworkers reported that COVID-19 has resulted in a major reduction in the colorectal surgical caseload in Italy [12]. Thompson et al. pointed that their daily endoscopy volume was cut by over $80 \%$ and ambulatory endoscopy practice was closed in Brigham and Women's Hospital, Harvard Medical School [13]. To date, COVID-19 outbreak has come into resuming period in China, routine medical activities begin to return to normal. After experienced massive pressure fighting against the virus, we have the extra time to estimate the losses in the field of GI endoscopy during COVID-19 outbreak period.

To our best knowledge, this is the first nationwide survey providing insights on changes of GI endoscopy practices in China during the pandemic. Our results showed that there
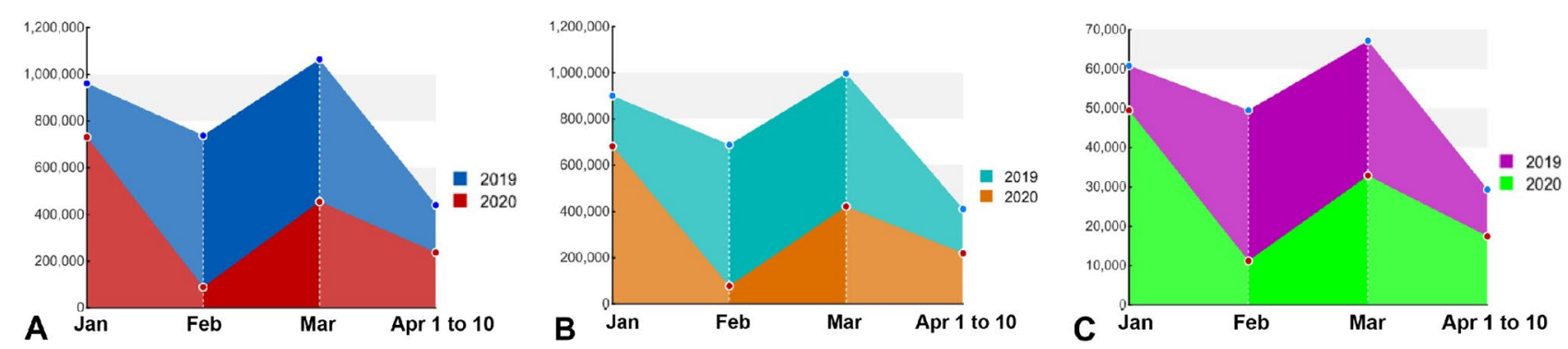

Fig. 3 Changes of GI endoscopic procedures volume per months between 2019 and 2020. a Overall; b Diagnostic procedures; c Therapeutic procedures 


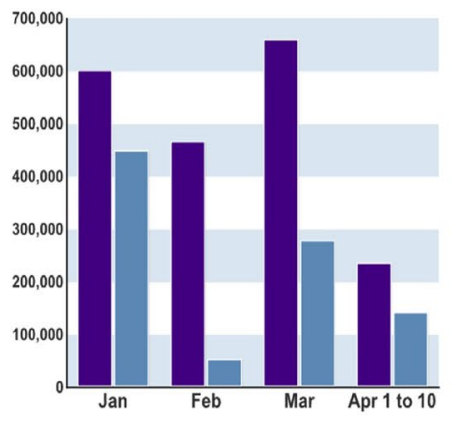

A. EGD

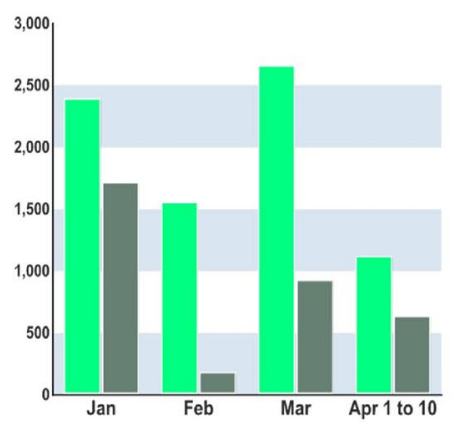

D. Capsule endoscopy
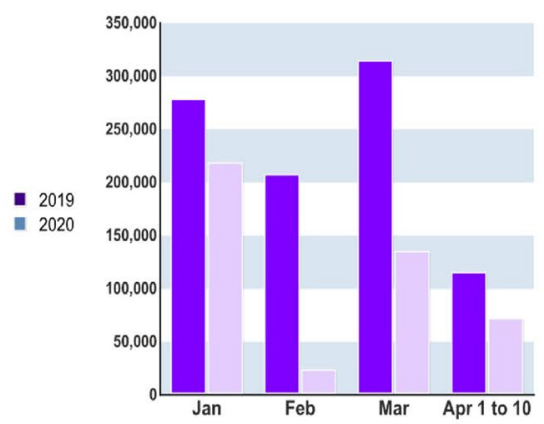

B. Colonoscopy

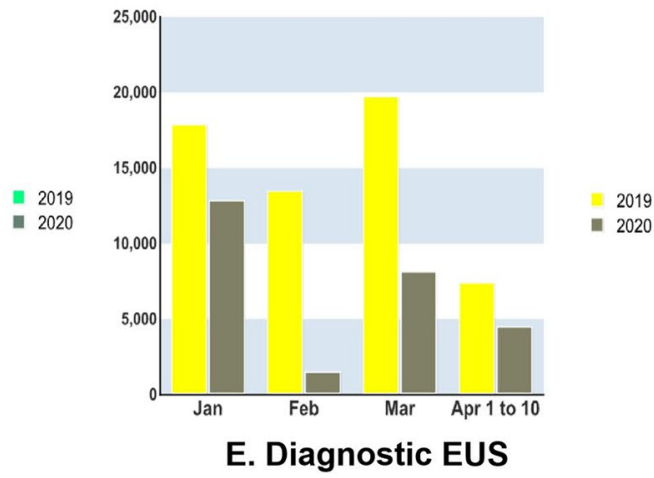

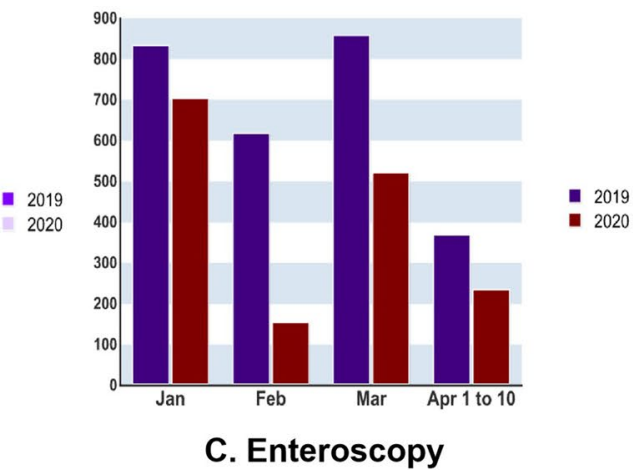
2019

Fig. 4 Distribution of diagnostic GI endoscopic procedures between 2019 and 2020

was a dramatic decrease of GI procedures and participants getting training related to COVID-19 outbreak. The remarkable reduction in endoscopic activities can be due to the following reasons: (i) The practice of blocking traffic and lockdown of towns restricted people for reference to the superior hospital in another city. (ii) Endoscopists and nurses were relocated to other departments to assist with COVIDpositive patients, such as intensive care unit or emergency ward. So there would be a lack of endoscopic unit personnel. (iii) Several recommendations and guidance worldwide called to limit endoscopic procedures to urgent endoscopic interventions and deferral of elective non-urgent endoscopic procedures.

In our study, we found that reduced number of endoscopic procedures differed between geographic regions. As the highest-risk areas overwhelmed by the pandemic, Hubei province, had the most losses ratio of procedures (the volume in 2020 is a fifth of that in 2019). The reason was all electives in these regions were canceled, most medical resources were allocated to deal with the COVID-19 cases, and the available limited resources were devoted to only emergency therapeutic procedures. Another interesting finding is that Beijing had the highest number of reduced procedures, although the epidemic situation there was not severe. The reason for that is not difficult to understand. Beijing is the capital and political center of China, so prevention and control measures of COVID-19 there are much more strict than other regions in China. Not only were the endoscopic activities limited but large numbers of immigration workers to this city were restricted, which means the number of patients decreased.

As for the impact of the pandemic on various medical training, Amparore et al. reported that a large proportion of urology residents experienced a severe reduction ( $>40 \%$ ) or complete suppression ( $>80 \%)$ of training exposure in Italy [14]. Our results also indicated that participants of various endoscopic training declined drastically. The classical teaching models, lectures, seminars, hand-on-hand teaching and others are no longer safe and applicable in times of the pandemic. Implementation of alternative learning strategies, such as telemedicine, tele-mentoring of procedure, are warranted to mitigate adverse effects on endoscopists' training.

During the pandemic, endoscopic procedures are considered to be high risk. In northern Italy, Repici reported SARS-CoV-2 infection among nurses and physicians was confirmed in 12 endoscopy units, and six endoscopy personnel (three nurses and three physicians) required hospitalization [15]. Several organizations and societies have issued guidelines and position papers to instruct safe GI endoscopy practice during the pandemic [4-9]. The CSDE also issued guidance for endoscopic examinations on Feb 3, 2020 [10], which elaborated specific recommendations for endoscopy during the COVID-19 pandemic. Similar to recommendations from other societies, proper use of personal protective 

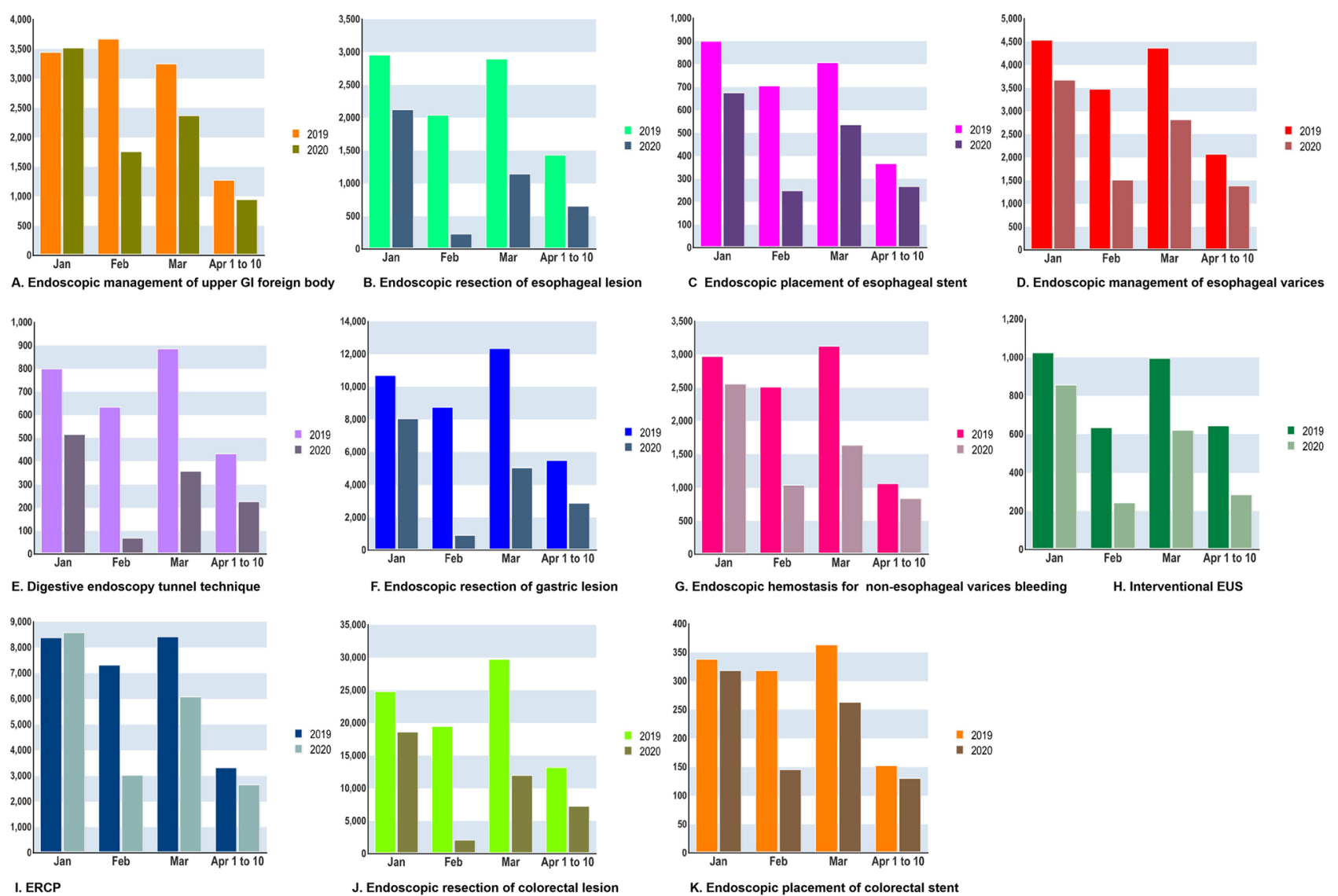

Fig. 5 Distribution of therapeutic GI endoscopic procedures between 2019 and 2020

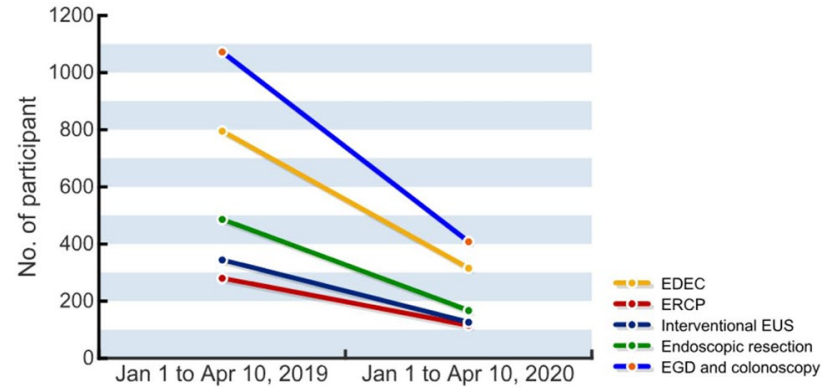

Fig. 6 Changes of participants number based on GI endoscopic training patterns between 2019 and 2020. EDEC: endoscopic detection of early GI cancer

equipment, risk stratification of patients, reduced normal endoscopic activities, postponing procedures, modified the waiting room, standardized reprocessing procedure for flexible endoscopes and others were written in the guidance. Due to high adherence to the above recommendations by CSDE, there was no endoscopy-related COVID-19 nosocomial infections reported in our study. In addition to the strict and standardized workflow needed in clinical practice, some emerging endoscopic devices can also play an important role in preventing virus transmission. A novel non-contact magnetically-controlled capsule endoscopy (MCE) system has been recently developed to avoid the direct contact between doctors and patients for upper endoscopic examination [16]. Furthermore, a disposable endoscope can have particular advantage. An ultrathin disposable endoscope has been applied for detection of upper gastrointestinal diseases, and shown excellent outcomes comparable to that of conventional endoscopes [17, 18].

The strongest strength of our study is that we provide the concrete impact of COVID-19 on GI endoscopic practice in mainland China, including various endoscopic procedures and training. Right now, the epidemic situation of COVID19 begin to become stable. But the situation in Europe and US is still very severe. Our results can provide references to these countries for estimating the loss of GI endoscopic practices during the period of COVID-19 pandemic.

We acknowledge that there are some limitations in this study. At first, because the survey duration was very short, just 7 days, data regarding the effect of COVID-19 precautions on endoscopic procedure time, complication rate and success rate was not available. Then, we didn't evaluate the mental condition of medical personnel in all centers. Since 
it has reported that COVID-19 triggered a wide variety of psychological problems, such as panic disorder, anxiety and depression in the general population of China [19], and a recent report demonstrated psychological stress in medical staffs was more severe than college students [20]. So it is necessary to conduct study to understand the psychological stress status of endoscopists and nurses in future. Third, lack of data on urgent or emergent endoscopic procedure also impacted our study. Finally, economic losses caused by endoscopic procedure reduction can't be assessed because of different medical reimbursement policy in different regions of China.

In conclusion, with the influence of the COVID-19 epidemic, there has been significant decease of GI endoscopy practice in mainland China. Further researches are urgently needed in relation to the full impact of COVID-19 on endoscopic quality, regional endoscopic development, and how to effectively manage endoscopic units after this pandemic.

Acknowledgements We express the high respect to all the medical workers who are at the first line of attack COVID-19, and acknowledge all the hospitals participated in this survey.

Author contributions Study conception and design: NC, XT and EL. Drafting of manuscript: XT and NC. Data acquisition: JF, LY, QW, XZ and RD. Data analysis and interpretation: LL, WZ, JX. Revision of manuscript, and final approval of manuscript: EL.

\section{Compliance with ethical standards}

Conflict of interest Dr. Ningli Chai, Dr. Xiaowei Tang, Dr. Enqiang Linghu, Dr. Jiancong Feng, Dr. Lu Ye, Dr. Qingzhen Wu, Dr. Xin Zhao, Dr. Runxiang Du, Dr. Longsong Li, Dr. Wengang Zhang and Dr. Jingyuan Xiang, all have no conflicts of interest or financial ties to disclose.

\section{Reference}

1. Zhu N, Zhang D, Wang W, Li X, Yang B, Song J, Zhao X, Huang B, Shi W, Lu R, Niu P, Zhan F, Ma X, Wang D, Xu W, Wu G, Gao GF, Tan W (2020) A novel coronavirus from patients with pneumonia in China, 2019. N Engl J Med 382:727-733. https://doi.org/10.1056/ NEJMoa2001017

2. https://covid19.who.int/. Accessed 19 April 2020.

3. Soetikno R, Teoh AY, Kaltenbach T, Lau JYW, Asokkumar R, Cabral-Prodigalidad P, Shergill A (2020) Considerations in performing endoscopy during the COVID-19 pandemic. Gastrointest Endosc 92(1):176-183. https://doi.org/10.1016/j.gie.2020.03.3758

4. Gu J, Han B, Wang J (2020) COVID-19: gastrointestinal manifestations and potential fecal-oral transmission. Gastroenterology 158(6):1518-1519. https://doi.org/10.1053/j.gastro.2020.02.054

5. Gralnek IM, Hassan C, Beilenhoff U, Antonelli G, Ebigbo A, Pellisè M, Arvanitakis M, Bhandari P, Bisschops R, Van Hooft JE, Kaminski MF, Triantafyllou K, Webster G, Pohl H, Dunkley I, Fehrke B, Gazic M, Gjergek T, Maasen S, Waagenes W, de Pater M, Ponchon T, Siersema PD, Messmann H, Dinis-Ribeiro M (2020) ESGE and ESGENA Position Statement on gastrointestinal endoscopy and the COVID-19 pandemic. Endoscopy 52(6):483-490. https://doi. org/10.1055/a-1155-6229
6. Chiu PWY, Ng SC, Inoue H, Reddy DN, Ling HuE, Cho JY, Ho LK, Hewett DG, Chiu HM, Rerknimitr R, Wang HP, Ho SH, Seo DW, Goh KL, Tajiri H, Kitano S, Chan FKL (2020) Practice of endoscopy during COVID-19 pandemic: position statements of the Asian Pacific Society for Digestive Endoscopy (APSDE-COVID statements). Gut 69(6):991-996. https://doi.org/10.1136/gutjn 1-2020-321185

7. Sociedad Española de Patología Digestiva, Asociación Española de Gastroenterología (2020) Recommendations by the SEPD and AEG, both in general and on the operation of gastrointestinal endoscopy and gastroenterology units, concerning the current SARS-CoV-2 pandemic (March, 18). Rev Esp Enferm Dig 112(4):319-322. https ://doi.org/10.17235/reed.2020.7052/2020

8. Castro Filho EC, Castro R, Fernandes FF, Pereira G, Perazzo H (2020) Gastrointestinal endoscopy during COVID-19 pandemic: an updated review of guidelines and statements from international and national societies. Gastrointest Endosc 92(2):440-445. https://doi. org/10.1016/j.gie.2020.03.3854

9. Sultan S, Lim JK, Altayar O, Davitkov P, Feuerstein JD, Siddique SM, Falck-Ytter Y, El-Serag HB (2020) AGA Institute Rapid Recommendations for Gastrointestinal Procedures During the COVID19 Pandemic. Gastroenterology 159(2):739-758. https://doi. org/10.1053/j.gastro.2020.03.072

10. Recommendation of CSDE for Endoscopy Works During the Pandemics of COVID-19 (in Chinese). https://www.csde.org.cn/news/ detail.aspx?article_id $=2883$

11. https://2019ncov.chinacdc.cn/2019-nCoV/. Accessed 19 April 2020.

12. Lisi G, Campanelli M, Spoletini D, Carlini M (2020) The possible impact of COVID-19 on colorectal surgery in Italy. Colorectal Dis 22(6):641-642. https://doi.org/10.1111/codi.15054

13. Thompson CC, Shen L, Lee LS (2020) COVID-19 in endoscopy: Time to do more? Gastrointest Endosc 92(2):435-459. https://doi. org/10.1016/j.gie.2020.03.3848

14. Amparore D, Claps F, Cacciamani GE, Esperto F, Fiori C, Liguori G, Serni S, Trombetta C, Carini M, Porpiglia F, Checcucci E, Campi $\mathrm{R}$ (2020) Impact of the COVID-19 pandemic on urology residency training in Italy. Minerva Urol Nefrol 72(4):505-509. https://doi. org/10.23736/S0393-2249.20.03868-0

15. Repici A, Pace F, Gabbiadini R, Colombo M, Hassan C, Dinelli M (2020) Endoscopy units and the COVID-19 Outbreak: a multi-center experience from Italy. Gastroenterology 159(1):363-366. https://doi. org/10.1053/j.gastro.2020.04.003

16. https://www.clinicaltrials.gov/ct2/show/NCT0432095 3 ? cond $=$ COVID-19+endoscopy $\&$ draw $=2 \&$ rank $=3$. Accessed 22 April 2020

17. Kang D, Lim CH, Choi MG, Lee H, Kim JS, Cho YK, Park JM, Cho YS, Lee BI, Lee IS (2019) An operable, portable, and disposable ultrathin endoscope for evaluation of the upper gastrointestinal tract. Dig Dis Sci 64(7):1901-1907. https://doi.org/10.1007/s1062 0-019-5478-0

18. Huynh DK, Toscano L, Phan VA, Ow TW, Schoeman M, Nguyen NQ (2017) Ultrathin disposable gastroscope for screening and surveillance of gastroesophageal varices in patients with liver cirrhosis: a prospective comparative study. Gastrointest Endosc 85(6):12121217. https://doi.org/10.1016/j.gie.2016.11.019

19. Qiu J, Shen B, Zhao M, Wang Z, Xie B, Xu Y (2020) A nationwide survey of psychological distress among Chinese people in the COVID-19 epidemic: implications and policy recommendations. Gen Psychiatr 33(2):e100213. https://doi.org/10.1136/gpsych-2020100213

20. Wu W, Zhang Y, Wang P, Zhang L, Wang G, Lei G, Xiao Q, Cao X, Bian Y, Xie S, Huang F, Luo N, Zhang J, Luo M (2020) Psychological stress of medical staffs during outbreak of COVID-19 and adjustment strategy. J Med Virol. https://doi.org/10.1002/jmv.25914 
Publisher's Note Springer Nature remains neutral with regard to jurisdictional claims in published maps and institutional affiliations. 